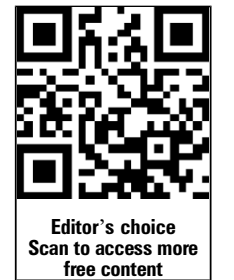

${ }^{1}$ University of Bristol Institute of Clinical Neurosciences, Frenchay Hospital, Bristol, UK ${ }^{2}$ Department of Neurology, North Bristol Trust, Frenchay Hospital, Bristol, UK

${ }^{3}$ Department Neurology, University of Bristol, Frenchay Hospital, Bristol, UK ${ }^{4}$ Neurology Department, University of Bristol, Institute of Clinical Neurosciences, Frenchay Hospital, Bristol, UK

\section{Correspondence to} Professor Neil J Scolding, Neurology Department, University of Bristol, Institute of Clinical Neurosciences, Frenchay Hospital, Bristol BS16 1LE, UK; n.j.scolding@bristol.ac.uk

Received 15 October 2012 Revised 14 January 2013 Accepted 15 January 2013 Published Online First 16 February 2013
To cite: Rice CM, Cottrell D, Wilkins A, et al. J Neurol Neurosurg Psychiatry 2013;84:1100-1106.

\title{
Primary progressive multiple sclerosis: progress and challenges
}

\author{
Claire M Rice, ${ }^{1}$ David Cottrell, ${ }^{2}$ Alastair Wilkins, ${ }^{3}$ Neil J Scolding ${ }^{4}$
}

\section{ABSTRACT}

Primary progressive multiple sclerosis (MS) has long been recognised as presenting great difficulties to our management of what is increasingly a treatable neurological disease. Here we review some basic and clinical aspects of primary progressive MS, and describe how the disorder in fact offers powerful insights and opportunities for better understanding multiple sclerosis, and from a practical perspective an invaluable clinical substrate for studying and treating progressive disability in MS. Difficult hurdles remain, however, and these too are reviewed.

\section{INTRODUCTION}

From its first historical depictions, multiple sclerosis has always been described and diagnosed by its clinical semiology, its particular and peculiar clinical pattern and course. And intrinsic to this defining description, it was explicitly recognised from the first that two types of clinical processes could occur: the acute and almost eponymous relapse, and chronic, persistent progressive disease. As the decades passed, so the labels applied to different patterns of clinical course increased-relapsing-remitting, relapsing-progressive, primary progressive, secondary progressive, progressive-relapsing, benign, fulminant and so onbut all are permutations and combinations of the two first-noted clinical phenomena, the acute relapse and progression. Most patients- $85-90 \%$ present with the former, the remainder with progression-onset disease: primary progressive multiple sclerosis (MS).

\section{CLINICAL FEATURES AND DIAGNOSIS}

It is curious, and rather little emphasised (at least in the last 50 years $^{1}{ }^{2}$ ) that the clinical features of primary progressive multiple sclerosis (PPMS) are so often very different from those of acute MS relapses. The latter include optic neuritis (usually unilateral) in approximately $25 \%$ of cases, brainstem events (around 45\%) and partial spinal cord syndromes, often exclusively sensory, often involving sphincter and/or sexual dysfunction. By contrast, primary progressive MS most commonly presents with a spinal syndrome, a spastic paraparesis usually with no clear sensory level $(80-85 \%$ cases). Some $10-15 \%$ present with progressive cerebellar ataxia, and a smaller number with cognitive, other brainstem or visual symptoms (2$4 \%) .{ }^{3}$ Interestingly, PPMS appears to exhibit only the slightest gender bias (1.1-1.3 to 1 ) unlike the 3:1 female to male predominance of MS overall ${ }^{3}$; the mean age of onset is greater ( 40 vs $\sim 30-$ rather similar to the average age of onset of secondary progression in those with relapse onset disease), and it is almost never seen (or at least recognised) in childhood.

With regard to clinical course, in the London Ontario Cohort, PPMS patients required unilateral assistance to walk (disability status score (DSS) 6) some 8 years after presentation, and became wheelchair-bound (DSS 8) after 18 years. ${ }^{3}$ Age of onset, gender or clinical presentation onset did not appear to influence the rate of progression. However, the rate of initial decline (from onset to DSS 3) was of some value as a prognostic indicator, correlating with an accelerated time to expanded disability status scale (EDSS) 8. Early imprinting of the disease process in PPMS therefore seems to occur (as it does in those with frequent relapses in the early years of relapsing-remitting disease).

The similarities between the clinicoanatomical features of primary and secondary progressive MS might have long ago suggested similar pathological substrates for any form of progression, just as these clinicoanatomical differences between primary progressive and relapse onset disease have implied dissimilar pathophysiology, but it was only when axon loss was rediscovered in the 1990s by Trapp's group in the US and Ferguson's in the UK that these distinctions became more appreciated. The almost non-overlapping nature of the differential diagnosis of these two presentations of MS has, however always been apparent (see table 1).

The investigation of suspected PPMS arguably needs to be more rigorous than that of its relapsing-remitting counterpart. Often, a confident diagnosis is far more difficult to achieve: PPMS can commonly be a diagnosis of exclusion, and the passage of time is often an important element. The required investigations can largely be deduced from the list of mimics in table 1 (which includes infective and other inflammatory conditions largely as a matter of completeness: few show the slow, relentless clinical course of PPMS).

It is worth adding that, in the diagnosis of MS, MRI scanning of the spinal cord can occasionally be far more informative than that of the brain, nonspecific lesions being all but non-existent in the cord. It should also be noted that the pattern of MR change seen in PPMS is not objectively distinguishable from that of relapsing-remitting multiple sclerosis (RRMS). Similarly, spinal fluid examination, an essential part of the investigation of possible PPMS (whereas some now regard it as optional in relapsing-remitting (RR) disease), in containing oligoclonal bands in some 80-90\% cases, shows no features that distinguish primary progressive (PP) from RR MS. (That said, the 
Table 1 The differential diagnosis of primary progressive multiple sclerosis

\begin{tabular}{ll}
\hline Primary progressive MS & Differential diagnosis \\
\hline Degenerative & \\
MND & Infective/Inflammatory \\
Structural (c. spine/Chiari) & HIV \\
Hereditary & Syphilis \\
HSP—SCAs & Prions \\
Leukodystrophies (AMN, Krabbe's), PKU & Vasculitis, sarcoid, lupus \\
Metabolic & Schistosomiasis, Brucellosis \\
Vitamins B12, E & Neoplastic (paraneoplasia) \\
Copper & Idiopathic/cryptic \\
Hypothyroidism & \\
Toxic-phenytoin, lathyrism, nitric oxide & \\
Alcohol & \\
\hline AMN, & \\
\hline
\end{tabular}

AMN, adrenomyeloneuropathy; HSP, hereditary spastic paraplegia; MND, motor neuron disease; NO, nitric oxide; PKU, phenylketonuria; SCA, spinocerebellar ataxia.

cellular reaction not uncommonly seen in acute relapses is very unusual in PPMS.) Reaching a diagnosis of PPMS when oligoclonal bands are unequivocally negative is difficult, but measuring evoked potentials, particularly assessing multiple pathways, can be extremely helpful.

The emergence of 'diagnostic criteria' in MS can be particularly useful for standardisation in clinical trials and in epidemiological studies (a justification easier to sustain had they not required repeated revision and updating), but it should be stressed that for PPMS, such criteria are not evidence-based and await validation.

\section{ONE DISEASE OR TWO?}

The similarities mentioned above-in clinical features (compared with secondary progressive disease), spinal fluid and MR findings, begin to address the question some have posed of whether PP and relapse onset MS are one and the same disease-or whether, in parallel with neuromyelitis optica, for example, primary progressive disease will come to be seen as a distinct disorder. The consensus at present is against the latter ${ }^{5}$ : that primary progressive disease is but one phenotypic manifestation of MS, not radically different from relapse-onset disease. In addition to these similarities (see box 1), the facts that 6-10\% PPMS patients develop relapses at some point in their disease course, and that in families that include multiple members with MS, both phenotypes are seen (indeed this may be true in identical twins, each with MS) also point towards this

\section{Box 1 RR and PPMS-one disease or two?}

- MRI-not objectively distinguishable

- CSF banding-not objectively distinguishable

- Evoked potentials - not objectively distinguishable

- Genetics - not distinguishable

- Neuropathology-not distinguishable

- Clinical features - not distinct from secondary progressive multiple sclerosis

$\mathrm{RR}$, relapsing-remitting, PPMS, primary progressive multiple sclerosis; CSF, cerebrospinal fluid.
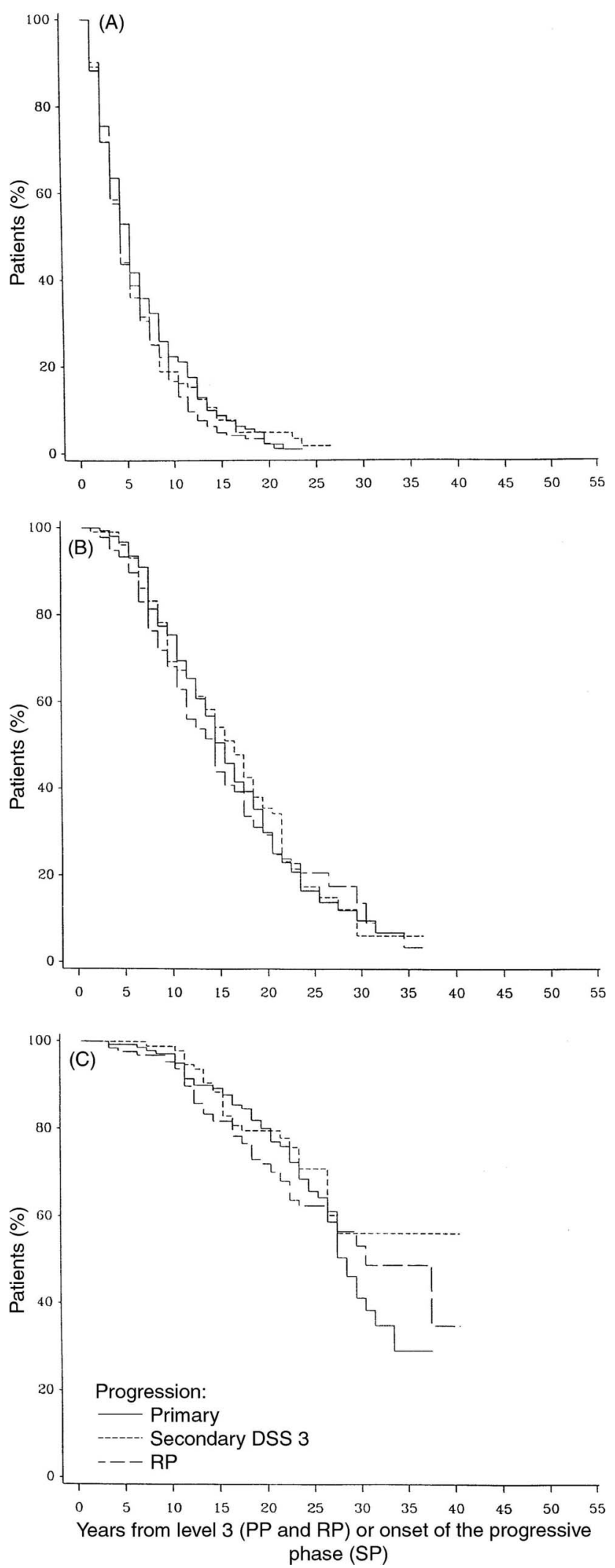

Figure 1 The figure shows the distribution of time taken to progress from DSS 3 to DSS 6 (A), 8 (B) and 10 (C) in SPMS patients compared with that for the time taken from the onset of MS to DSS 10 in PP and $\mathrm{RP}$ patients. DSS, disability status score; $\mathrm{PP}$, primary progressive; $\mathrm{RP}$, relapsing-progressive; SP, secondary progressive; SPMS, secondary progressive multiple sclerosis. Reproduced with permission from Kremenchutzky M, et al. Brain 1999;122:1941-50. 
being one disease, not two. Finally, the natural history of disability progression in PPMS appears virtually identical to that of secondary progressive disease when compared from onset of the progressive phase (figure $1 \mathrm{~A}-\mathrm{C}$ ). ${ }^{36}$

\section{MANAGEMENT}

The (generally accepted) pathobiological identity of PPMS with relapse onset disease has implications for therapy. At present, there are no useful disease-modifying treatments for secondary progressive MS; nothing reverses, stops or even appears significantly to slow progressive disability once established, and we can safely infer that the same applies to PPMS. Conversely, we might also conclude that, if we wish to find treatments that alter the course of progression, we might do best to test putative therapies in patients with PPMS, since the (near) absence of relapses creates a far more reliable substrate for assessing their impact, freed from the distracting and misleading 'noise' of relapse activity. Few would doubt that any agent helping in PPMS would be similarly effective in secondary progression.

Sadly, there are no such treatments at present, but this by no means amounts to therapeutic impotence. A wide variety of symptomatic drugs and interventions, beyond the scope of this article but excellently reviewed elsewhere ${ }^{7}$ can be of major benefit in patients with progressive MS-whether for pain, fatigue, depression, bladder incontinence, impotence, spasticity or tonic spasms. The first symptomatic drugs to improve mobility are beginning to emerge, if of limited efficacy, ${ }^{9}$ while treatments to help ataxia, tremor and nystagmus remain very poor.

\section{FUTURE THERAPEUTIC APPROACHES FOR PPMS}

There are two aspects of 'disease modification' in relation to progressive MS: preventing or delaying the onset of progression, and modifying its course once it is established. The former relates to relapse-onset disease (although the appearance of MRI changes an extraordinary 10 years prior to clinical presentation of PPMS ${ }^{10}$ implies a preclinical phase that could represent an important therapeutic opportunity). In RRMS, it seems likely, though is as yet unproven, that as more effective relapsepreventing immunotherapies emerge, these will be confirmed to delay the onset of secondary progression. ${ }^{11-13}$ Indeed, since this transition ('RR to SP') determines the long-term prognosis of an individual presenting with relapses far more accurately than relapse rate or new MRI activity, making the onset of secondary progression a primary outcome measure for trials of RR patients might represent a significant advance in trial design.

Slowing, let alone halting, progression remains a serious challenge. There is a consensus that current immunotherapies do not significantly influence the course of progression once established in relapse onset disease. ${ }^{11}{ }^{14}$ Valuable efforts have been made to study their effect in PPMS, but where this has been done, again no impact has emerged. ${ }^{15-18}$

While the question of whether progression in multiple sclerosis is principally a neurodegenerative disorder, or whether that degeneration is still driven by a 'smouldering' low-grade inflammatory process sequestered within the central nervous system $(\mathrm{CNS})^{19}$ has not entirely been resolved, the therapeutic impetus appears to have shifted in recent years towards exploring nonimmune neuroprotective strategies in progressive MS - not least because of the lack of effect of immune approaches. A phase 2 trial of lamotrigine ${ }^{20}$ has proved negative, but a comparable trial of phenytoin is planned and one of topiramate is already underway (http://clinicaltrials.gov/ct2/show/NCT00217295), there being much interest and a persuasive evidence base suggesting that sodium channel blockade can reduce axonal injury in experimental allergic encephalomyelitis (EAE). ${ }^{21} 23$

There is, similarly, a wealth of evidence that cannabinoids are neuroprotective in cell culture paradigms and MS disease models. ${ }^{2426}$ The first successfully executed multicentre randomised controlled trial of cannabis in $\mathrm{MS}^{27}$ primarily explored its symptomatic effects on spasticity, but a later subgroup analysis raised the possibility of a clinically relevant neuroprotective effect, and a large phase 3 trial of cannabinoids has now been completed. While this showed no benefit in primary outcome disability measures (http://www.ctu.mrc.ac.uk/news_and_press_releases/news_archive/ cupid_30052012.aspx), subgroup analyses suggested promise in individuals less disabled at onset.

Riluzole, licensed for amyotrophic lateral sclerosis (ALS) and which inhibits glutamate transmission, is currently being trialled in patients with MS (http://clinicaltrials.gov/ct2/show/ NCT00501943), not least since excitotoxicity and oxidative stress are increasingly considered important therapeutic targets. $^{28}$

This is plainly in effect a completely new field, and such trials have offered powerful validation of the methodology in 'disability progression trials', while the increasing interest also shown by the pharmaceutical industry in developing treatments for progressive disease is a further encouraging sign.

\section{Growth factors}

Neurotrophins have also been to a great extent considered as neuroprotective agents in progressive MS. This is partly because there is good evidence that myelin and oligodendrocyte-derived growth factors support axons, and that their loss contributes to axon loss, ${ }^{29} 33$ and partly because of the promiscuous protective effects of such agents irrespective of the mechanism of injurya bonus when the precise mediators of axon and neuron damage remain to be defined. However, and notwithstanding our rapidly expanding knowledge of the biology of neurotrophins, the search for therapeutically useful neurotrophic factors has a rather long and dispiriting history. Clinical trials in disorders ranging from stroke and motor neuron disease to sensory neuropathy have all failed, the agents invariably proving either intolerable or ineffective. A single early phase clinical trial of insulin-like growth factor (IGF)-1 in MS was similarly unfruitful. ${ }^{34}$

\section{STEM CELL THERAPIES}

The original rationale of developing stem cell therapies was not so much to stop progression as to reverse disability by repairing damage, and the means of achieving this was by replacing oligodendrocytes by injecting their precursors. But substantial changes in our understanding of tissue damage in chronic MS have in effect shifted the paradigm of cell therapy. The realisation that proliferative oligodendrocyte progenitors exist in the adult human brain, ${ }^{35}$ and that significant numbers of these cells appear in MS lesions, ${ }^{36}{ }^{38}$ undermined the rationale of adding more cells. The apparent presence of endogenous neural progenitors or stem cells ${ }^{39}$ adds further doubt to this approach. That spontaneous remyelination is in fact rather more widespread than originally perceived-and this quite specifically includes PPMS ${ }^{40}$-also calls into question a strategy based solely on increasing remyelination. But in addition, in secondary but particularly primary progressive MS, the relationship of demyelinated lesions to accumulating disability is highly questionable. It is generally now accepted that so-called 'normalappearing' tissue in the MS brain and spinal cord is not normal, and that diffuse tissue damage particularly affecting neurons and 
axons plays the major pathophysiological role in progressionso that targeted injection of cells into specific lesions, even if it did lead to successful local myelin repair, would probably have little if any effect on progressive disability.

These significant advances in our understanding of multiple sclerosis have not so much outstripped advances in stem cell biology as they have altered the way we think about cell therapy. Additionally and importantly, they have focused attention on the underlying molecular mechanisms of remyelination failure, ${ }^{41}$ a better appreciation of which may well yield pharmacological approaches to promoting remyelination, and with this axonal stabilisation. ${ }^{42}{ }^{43}$ 'Traditional' pharmacotherapeutic interventions to promote remyelination, using the circulation to distribute any effective agent throughout the brain and spinal cord, plainly are better suited to the diffuse damage that we now know underlies progression, in a way that injecting cells into discrete lesions does not. Of the underlying biological processes relating to MS, our knowledge continues to progress: for example, very recent studies cast some doubt on the extent to which successful remyelination can help prevent progressive axonal loss. (Briefly, and with the caveat that this study explored a cuprizone demyelinating model and cuprizone can affect not just myelin but axons, it now is suggested that demyelinated axons which are then remyelinated still can and do degenerate. ${ }^{44}$ )

Exploitation of the circulation as a means of widespread, 'diffuse' delivery also underpins the alternative emerging cell therapeutic approach that seeks to use bone marrow cells. Circulating mesenchymal stem cells (MSCs), endogenous (released from the marrow in health, and more so in disease) and exogenous (delivered intravenously), 'home' specifically to areas of tissue damage or inflammation ${ }^{45} 47$-including those within the brain and spinal cord. ${ }^{48} 49$

This therapeutic approach differs in a second major way from the earlier stem cell paradigm in no longer having as its principal aim the replacement of oligodendrocytes to enhance remyelination. Rather, bone marrow cell therapy for MS is based on our rapidly emerging understanding of the many potentially beneficial properties of several bone marrow stem cell populations, properties that could, and in experimental systems do have reparative, neuroprotective and disease modifying elements.

It now seems clear that the normal physiological (or perhaps, rather, pathophysiological) function of several bone marrow cell subpopulations is spontaneous tissue repair. ${ }^{47} 5051$ MSCs have been most studied, and exhibit an almost breathtaking range of properties and behaviours. They have pronounced immunomodulating and immunosuppressive properties. ${ }^{52} 55$ Second, isolated MSCs and non-cultured, bone marrow mononuclear cells promote myelin repair following experimental (non-immune mediated) demyelination. ${ }^{56}$ MSCs may indirectly stimulate remyelination, and other reparative effects, by recruiting and activating endogenous neural stem cells. ${ }^{58-60}$ They can reduce gliotic scar formation. ${ }^{6165}$ MSCs have powerful neuroprotective properties, ${ }^{66} 67$ again independent of their anti-inflammatory activity, although protection against oxidative stress applies to immune and non-immune tissue damage. ${ }^{68} 69$ Finally (so far), MSCs are able to fuse with some specific cell types, particularly during tissue damage (perhaps particularly cerebellar Purkinje cells), apparently representing a further mechanism by which MSCs may offer protection (or 'rescue' damaged cells). ${ }^{68} 70$ There is indirect evidence that this happens not just experimentally but in MS itself (Kemp et al, Brain in press).

Two further points should be stressed: first, that other- indeed, probably all-adult tissues also harbour MSCs, ${ }^{71}$ and such tissues may also serve as a source of therapeutic cells. ${ }^{72}$ Second, other
non-MSC subpopulations of bone marrow cells could also promote tissue repair, also by using a wide variety of effector mechanisms, including haematopoetic stem cells, ${ }^{73} 78$ Stro-1 positive cells, ${ }^{79} \mathrm{CD} 133+$ ve cells, ${ }^{84} 86$ multipotent adult progenitor cells (MAPCs) and others. ${ }^{87} 89$ In recent fascinating rodent studies, bone marrow-derived monocytes were shown to have remarkable abilities quite literally to 'rejuvenate' myelin repair in experimental remyelination. ${ }^{90}$

Concerning possible translation, while it is the case that bone marrow cell therapy in patients with progressive MS would use autologous cells, it would be wrong to assume that adult stem cell therapy would necessarily be wholly free from hazard. ${ }^{91}$ The repeated cell cycling and expansion required to prepare purified, selected MSCs (or other subpopulations) can induce unwelcome genetic instability ${ }^{92}$ - quite apart from compromising repair capacities. ${ }^{95} 99$ And while malignant, donor-derived tumours have not been reported in patients receiving MSCs, including the now several hundred treated in trials for various cardiac diseases, ${ }^{100}$ a recent report does indicate that MSCs directly injected intraventricularly can form non-proliferating cellular mass lesions. ${ }^{101}$

However, the use of non-manipulated, mixed 'primary' bone marrow cell harvests-without purification, cell culture or expansion, and delivered intravenously rather than by injection into the brain, avoids these theoretical or experimental hazards, and has been shown to be effective in a number of non-neurological disorders. ${ }^{102} 103$ Trials using such cells have also been commenced in stroke. ${ }^{104}$ We have now commenced studies in progressive MS, with promising results in a very small cohort of patients with progressive disease ${ }^{105}$; a phase two trial (ACTiMuS)-which will include a discrete subgroup with primary progressive multiple sclerosis-is to commence imminently.

\section{Challenges to PPMS therapeutic trials}

Notwithstanding PPMS offering an attractive 'pure progression' cohort to study therapeutics for preventing disability progression, there remains a relative dearth in therapeutic trials in comparison with its relapsing counterparts. This is probably multifactorial. Patients with PPMS are generally older, and so are more likely to have concomitant diseases, inevitably complicating trial design, recruitment and interpretation-arthritis, cardiovascular and respiratory conditions can all impair mobility and so affect the EDSS. Such conditions could also limit the use of more 'aggressive' therapies in this cohort. Additionally, PPMS patients generally have higher levels of disability and often strained social networks that can limit even the most dedicated of patients and their carers in what are often arduous and demanding clinical trials. In the authors' experience of such PPMS trials disappointment almost inevitably occurs as the trial participant and their carers watch their disease progress. Modest slowing of disability progression is unlikely to be apparent to the trial participant (or investigator), and waiting for outcomes from such trials often takes many years. Dropout rates therefore for trials of PPMS patients are likely to be considerably higher than their relapsing counterparts. Such potentially high dropout rates must be seriously considered in advance if failure of long and often very expensive studies is to be avoided.

Calculations of population size for therapeutic trials have been deduced from the London, Ontario longitudinal database, ${ }^{106}$ based on the likelihood of a PPMS population progressing along each DSS point. The spinally biased DSS is arguably more suited to progressive cohorts rather than its relapsing counterparts, but large numbers of patients and long periods of study are still required to prove a treatment effect. A later 
PPMS natural history study from the British Columbia cohort ${ }^{107}$ found slower progression, implying that even larger numbers of patients would be needed.

The difference in these studies is, in our view, significant, and likely due to discrepancies in defining patients as having PPMS. Certainly, a proportion of individuals initially thought to have PPMS do not subsequently (and often over a period of decades) 'progress' along the EDSS. In the British Columbia cohort, 9\% had not reached EDSS 3 by 10 years. Whether these are truly PPMS patients is debatable. However, the largest completed PPMS trial to date, the PROMiSe trial ${ }^{17}$ comparing glatiramer with placebo over a 3-year period highlighted the difficulties of using PPMS cohorts, with fewer patients sustaining an increase in disability than expected. Patient selection for PPMS trials is crucial to success or failure.

Additionally, the EDSS is not an ordinal scale, either in time or level of disability. PPMS patients at DSS 6-9 have substantially longer 'staying times' at each level ${ }^{3}$; and so recruiting pre-DSS 6.0 patients to trials will reduce overall numbers required. But most PPMS patients present with a DSS of 4.0 or greater (mean initial DSS 5 for London cohort and EDSS 4.9), and PPMS trials often require documented EDSS progression in the preceding year-so the optimum population is greatly restricted, and such patients are already becoming hard to identify. Using early stage 'PPMS patients' also increases the risk of recruiting misdiagnosed patients including 'non-progressors' and inevitably leads to huge disappointment to those patients deemed 'past-it' in the exclusion criteria.

With the renewed emphasis on treating progression, and a wide range of possible new therapeutics, more sensitive methods of monitoring progressive MS are desperately needed. The enormous difficulty facing trial design for studies of interventions to prevent (or reverse) progressive disability in MS is that of end points. Clinical scales are currently imperfect but surrogate measures arguably even more so-and clinical parameters plainly are more relevant to patients than surrogates. But progression is slow, and so using purely clinical measures would necessitate studying large numbers of patients over (probably) a minimum of 5 years. Plainly the costs then become enormously expensive—often prohibitively so.

Better surrogate measures would of course substantially reduce numbers and duration, and so have major impact on trial costs. Potential options include novel MRI techniques, optical coherence tomography, and neurophysiological measures of conduction in multiple CNS pathways (the latter, objective and functional, in our opinion the most attractive). Any such surrogates must, however, be rigorously validated in longitudinal studies before the EDSS can be rationally abandoned.

Funding The Burden Neurological Institute MS Stem cell programme is supported by the Silverman Family Foundation.

Competing interests None.

Provenance and peer review Commissioned; externally peer reviewed.

\section{REFERENCES}

1 Bennetto L, Burrow J, Sakai $H$, et al. The relationship between relapse, impairment and disability in multiple sclerosis. Mult Scler 2011;17:1218-24.

2 Muller R. Studies on disseminated sclerosis with special reference to symptomatology, course and prognosis. Acta Med Scand 1949;133:1-214.

3 Cottrell DA, Kremenchutzky M, Rice GP, et al. The natural history of multiple sclerosis: a geographically based study. 5 . The clinical features and natural history of primary progressive multiple sclerosis. Brain 1999;122(Pt 4):625-39.

4 Stevenson VL, Miller DH, Rovaris M, et al. Primary and transitional progressive MS. Neurology 1999:52:839.
5 Antel J, Antel S, Caramanos Z, et al. Primary progressive multiple sclerosis: part of the MS disease spectrum or separate disease entity? Acta Neuropathologica 2012;123:627-38

6 Confavreux C, Vukusic S, Moreau T, et al. Relapses and progression of disability in multiple sclerosis. N Engl J Med 2000;343:1430-8.

7 Thompson AJ, Toosy AT, Ciccarelli O. Pharmacological management of symptoms in multiple sclerosis: current approaches and future directions. Lancet Neurol 2010;9:1182-99.

8 Rice CM, Wilkins A. Symptomatic treatment for progressive multiple sclerosis. In: Wilkins A, ed. Progressive Multiple Sclerosis. A Wilkins, London: Springer, 2012:147-87

9 Hauser SL, Johnston SC. 4-aminopyridine: new life for an old drug. Ann Neurol 2010;68:A8-9.

10 McDonnell GV, Cabrera-Gomez J, Calne DB, et al. Clinical presentation of primary progressive multiple sclerosis 10 years after the incidental finding of typical magnetic resonance imaging brain lesions. Mul Scler 2003;9:204-9.

11 Coles AJ, Cox A, Le PE, et al. The window of therapeutic opportunity in multiple sclerosis Evidence from monoclonal antibody therapy. J Neurol 2006: 253:98-108.

12 Coles AJ, Compston DA, Selmaj KW, et al. Alemtuzumab vs. interferon beta-1a in early multiple sclerosis. N Engl J Med 2008;359:1786-801.

13 Polman $\mathrm{CH}, \mathrm{O}^{\prime}$ Connor PW, Havrdova $\mathrm{E}$, et al., the $\mathrm{A}, \mathrm{I}$. A randomized, placebo-controlled trial of natalizumab for relapsing multiple sclerosis. $N$ Engl J Med 2006;354:899-910.

14 The North American Study Group on Interferon beta-. Interferon beta-1b in secondary progressive MS. Neurology 2004;63:1788-95.

15 Montalban X, Sastre-Garriga J, Tintore $M$, et al. A single-center, randomized, double-blind, placebo-controlled study of interferon beta-1b on primary progressive and transitional multiple sclerosis. Mult Scler 2009;15:1195-205.

16 Hawker $\mathrm{K}, \mathrm{O}^{\prime}$ Connor $\mathrm{P}$, Freedman MS, et al. Rituximab in patients with primary progressive multiple sclerosis: results of a randomized double-blind placebo-controlled multicenter trial. Ann Neurol 2009:66:460-71.

17 Wolinsky JS, Narayana PA, O'Connor P, et al. Glatiramer acetate in primary progressive multiple sclerosis: results of a multinational, multicenter, double-blind, placebo-controlled trial. Ann Neurol 2007;61:14-24.

18 Rojas J, Romano M, Ciapponi A, et al. Interferon Beta for primary progressive multiple sclerosis. Cochrane Database Syst Rev 2010;1:(CD006643).

19 Lassmann $\mathrm{H}$. Mechanisms of neurodegeneration shared between multiple sclerosis and AlzheimerГÇÖs disease. J Neural Transm 2011;118:747-52.

20 Kapoor R, Furby J, Hayton T, et al. Lamotrigine for neuroprotection in secondary progressive multiple sclerosis: a randomised, double-blind, placebo-controlled, parallel-group trial. Lancet Neurol 2010;9:681-8.

21 Bechtold DA, Kapoor R, Smith KJ. Axonal protection using flecainide in experimental autoimmune encephalomyelitis. Ann Neurol 2004;55:607-16.

22 Black JA, Liu S, Hains BC, et al. Long-term protection of central axons with phenytoin in monophasic and chronic-relapsing EAE. Brain 2006;129:3196-208.

23 Kapoor R, Davies M, Blaker PA, et al. Blockers of sodium and calcium entry protect axons from nitric oxide-mediated degeneration. Ann Neuro/ 2003;53:174-80.

24 Jackson SJ, Baker D, Cuzner ML, et al. Cannabinoid-mediated neuroprotection following interferon-gamma treatment in a three-dimensional mouse brain aggregate cell culture. Eur J Neurosci 2004;20:2267-75.

25 Jackson SJ, Diemel LT, Pryce G, et al. Cannabinoids and neuroprotection in CNS inflammatory disease. J Neurol Sci 2005;233:21-5

26 Pryce $G$, Ahmed Z, Hankey DJ, et al. Cannabinoids inhibit neurodegeneration in models of multiple sclerosis. Brain 2003;126:2191-202.

27 Zajicek J, Fox P, Sanders H, et al. Cannabinoids for treatment of spasticity and other symptoms related to multiple sclerosis (CAMS study): multicentre randomised placebo-controlled trial. Lancet 2003;362:1517-26.

28 Gonsette RE. Oxidative stress and excitotoxicity: a therapeutic issue in multiple sclerosis? Mult Scler 2008;14:22-34.

29 Scolding N, Franklin R. Axon loss in multiple sclerosis. Lancet 1998;352:340-1.

30 Rodriguez $M$. A function of myelin is to protect axons from subsequent injury: implications for deficits in multiple sclerosis. Brain 2003;126:751-2.

31 Wilkins A, Chandran S, Compston A. A role for oligodendrocyte-derived IGF-1 in trophic support of cortical neurons. Glia 2001:36:48-57.

32 Wilkins $A$, Majed $H$, Layfield $R$, et al. Oligodendrocytes promote neuronal survival and axonal length by distinct intracellular mechanisms: a novel role for oligodendrocyte-derived glial cell line-derived neurotrophic factor. J Neurosci 2003:23:4967-74.

33 Wilkins A, Scolding N. Protecting axons in multiple sclerosis. Mult Scler 2008; 14:1013-25.

34 Frank JA, Richert N, Lewis $B$, et al. A pilot study of recombinant insulin-like growth factor-1 in seven multiple sderosis patients. Mult Scler 2002;8:24-9

35 Scolding NJ, Rayner PJ, Sussman J, et al. A proliferative adult human oligodendrocyte progenitor. NeuroReport 1995;6:441-5.

36 Scolding $N$, Franklin $\mathrm{R}$, Stevens $\mathrm{S}$, et al. Oligodendrocyte progenitors are present in the normal adult human CNS and in the lesions of multiple sclerosis. Brain 1998:121:2221-8 
37 Wolswijk G. Oligodendrocyte precursor cells in the demyelinated multiple sclerosis spinal cord. Brain 2002;125:338-49.

38 Chang A, Nishiyama A, Peterson J, et al. NG2-positive oligodendrocyte progenitor cells in adult human brain and multiple sclerosis lesions. J Neurosci 2000;20:6404-12.

39 Snethen $\mathrm{H}$, Love S, Scolding N. Disease-responsive neural precursor cells are present in multiple sclerosis lesions. Regen Med 2008;3:835-47.

40 Patrikios P, Stadelmann C, Kutzelnigg A, et al. Remyelination is extensive in a subset of multiple sclerosis patients. Brain 2006;129:3165-72.

41 Fancy SPJ, Kotter MR, Harrington EP, et al. Overcoming remyelination failure in multiple sclerosis and other myelin disorders. Exp Neurol 2010;225:18-23.

42 Fancy SP, Baranzini SE, Zhao C, et al. Dysregulation of the Wnt pathway inhibits timely myelination and remyelination in the mammalian CNS. Genes Dev 2009:23:1571-85

43 Mi S, Hu B, Hahm K, et al. LINGO-1 antagonist promotes spinal cord remyelination and axonal integrity in MOG-induced experimental autoimmune encephalomyelitis. Nat Med 2007;13:1228-33.

44 Manrique-Hoyos N, Jurgens T, Gronborg M, et al. Late motor decline after accomplished remyelination: impact for progressive MS. Ann Neurol 2012;71:227-44

45 Fox JM, Chamberlain G, Ashton BA, et al. Recent advances into the understanding of mesenchymal stem cell trafficking. $\mathrm{Br} J$ Haematol 2007:137:491-502

46 Karp JM, Leng Teo GS. Mesenchymal stem cell homing: the devil is in the details. Cell Stem Cell 2009:4:206-16.

47 Korbling M, Estrov Z. Adult stem cells for tissue repair. N Engl I Med 2003:349:570-82.

48 Gordon D, Pavlovska G, Uney JB, et al. Human mesenchymal stem cells infiltrate the spinal cord, reduce demyelination, and localize to white matter lesions in experimental autoimmune encephalomyelitis. I Neuropathol Exp Neurol 2010;69:1087-95.

49 Rice CM, Scolding N. Adult human mesenchymal cells proliferate and migrate in response to chemokines expressed in demyelination. Cell Adhes Migration 2010;4:235-40.

50 Phinney DG. Biochemical heterogeneity of mesenchymal stem cell populations: clues to their therapeutic efficacy. Cell Cycle 2007;6:2884-9.

51 Rice CM, Scolding NJ. Adult stem cells-reprogramming neurological repair? Lancet 2004;364:193-9.

52 Zhang J, Li Y, Chen J, et al. Human bone marrow stromal cell treatment improves neurological functional recovery in EAE mice. Exp Neurol 2005;195:16-26.

53 Gerdoni E, Gallo B, Casazza S, et al. Mesenchymal stem cells effectively modulate pathogenic immune response in experimental autoimmune encephalomyelitis. Ann Neurol 2007;61:219-27.

54 Zappia E, Casazza S, Pedemonte E, et al. Mesenchymal stem cells ameliorate experimental autoimmune encephalomyelitis inducing T-cell anergy. Blood 2005:106:1755-61

55 Gordon D, Pavlovska G, Glover CP, et al. Human mesenchymal stem cells abrogate experimental allergic encephalomyelitis after intraperitoneal injection and with sparse CNS infiltration. Neurosci Lett 2008;448:71-3.

56 Akiyama Y, Radtke C, Honmou O, et al. Remyelination of the spinal cord following intravenous delivery of bone marrow cells. Glia 2002;39:229-36.

57 Akiyama Y, Radtke C, Kocsis JD. Remyelination of the rat spinal cord by transplantation of identified bone marrow stromal cells. J Neurosci 2002;22:6623-30.

58 Munoz JR, Stoutenger BR, Robinson AP, et al. Human stem/progenitor cells from bone marrow promote neurogenesis of endogenous neural stem cells in the hippocampus of mice. Proc Natl Acad Sci USA 2005;102:18171-6.

59 Bai L, Lennon DP, Eaton V, et al. Human bone marrow-derived mesenchymal stem cells induce Th2-polarized immune response and promote endogenous repair in animal models of multiple sclerosis. Glia 2009;57:1192-203.

$60 \mathrm{Li}$ Y, Chen J, Zhang CL, et al. Gliosis and brain remodeling after treatment of stroke in rats with marrow stromal cells. Glia 2005:49:407-17.

61 Chen $Q$, Long $Y$, Yuan $X$, et al. Protective effects of bone marrow stromal cell transplantation in injured rodent brain: synthesis of neurotrophic factors. J Neurosci Res 2005:80:611-19.

62 Garcia R, Aguiar J, Alberti E, et al. Bone marrow stromal cells produce nerve growth factor and glial cell line-derived neurotrophic factors. Biochem Biophys Res Commun 2004;316:753-4.

63 Li Y, Chen J, Chen XG, et al. Human marrow stromal cell therapy for stroke in rat: neurotrophins and functional recovery. Neurology 2002;59:514-23.

64 Ye M, Chen S, Wang X, et al. Glial cell line-derived neurotrophic factor in bone marrow stromal cells of rat. NeuroReport 2005;16:581-4.

65 Wilkins A, Kemp K, Ginty M, et al. Human bone marrow-derived mesenchymal stem cells secrete brain-derived neurotrophic factor which promotes neuronal survival in vitro. Stem Cell Res 2009;3:67-70

66 Kemp K, Hares K, Mallam E, et al. Mesenchymal stem cell-secreted superoxide dismutase promotes cerebellar neuronal survival. J Neurochem 2009;114:1569-80.

67 Kemp K, Gray E, Mallam E, et al. Inflammatory cytokine induced regulation of superoxide dismutase 3 expression by human mesenchymal stem cells. Stem Cell $\operatorname{Rev} 2010 ; 6: 548-59$
68 Johansson CB, Youssef S, Koleckar K, et al. Extensive fusion of haematopoietic cells with Purkinje neurons in response to chronic inflammation. Nat Cell Biol 2008:10:575-83.

69 Nygren JM, Liuba K, Breitbach M, et al. Myeloid and lymphoid contribution to non-haematopoietic lineages through irradiation-induced heterotypic cell fusion. Nat Cell Biol 2008;10:584-92.

70 Kemp K, Gordon D, Wraith DC, et al. Fusion between human mesenchymal stem cells and rodent cerebellar Purkinje cells. Neuropathol Appl Neurobiol 2010; 37:166-78.

71 da Silva ML, Chagastelles PC, Nardi NB. Mesenchymal stem cells reside in virtually all post-natal organs and tissues. J Cell Sci 2006;119:2204-13.

72 Mosna F, Sensebe L, Krampera M. Human bone marrow and adipose tissue mesenchymal stem cells: a user's guide. Stem Cells Dev 2010;19:1449-70.

73 Zuba-Surma EK, Kucia M, Ratajczak J, et al. 'Small stem cells' in adult tissues: very small embryonic-like stem cells stand up! Cytometry A 2009;75:4-13.

74 Koshizuka S, Okada S, Okawa A, et al. Transplanted hematopoietic stem cells from bone marrow differentiate into neural lineage cells and promote functional recovery after spinal cord injury in mice. J Neuropathol Exp Neurol 2004:63:64-72

75 Takakura N, Watanabe T, Suenobu S, et al. A role for hematopoietic stem cells in promoting angiogenesis. Cell 2000;102:199-209.

76 Burt RK, Traynor AE, Oyama Y, et al. Plasticity of hematopoietic stem cells: enough to induce tolerance and repair tissue? Arthritis Rheum 2002;46:855-8.

77 Fu X, Sun X. Can hematopoietic stem cells be an alternative source for skin regeneration? Ageing Res Rev 2009:8:244-9.

78 Zhou P, Wirthlin L, McGee J, et al. Contribution of human hematopoietic stem cells to liver repair. Semin Immunopathol 2009;31:411-19.

79 Simmons PJ, Torok-Storb B. Identification of stromal cell precursors in human bone marrow by a novel monoclonal antibody, STRO-1. Blood 1991;78:55-62.

80 Psaltis PJ, Paton S, See F, et al. Enrichment for STRO-1 expression enhances the cardiovascular paracrine activity of human bone marrow-derived mesenchymal cell populations. J Cell Physiol 2010;223:530-40.

81 Stewart K, Monk P, Walsh S, et al. STRO-1, HOP-26 (CD63), CD49a and SB-10 (CD166) as markers of primitive human marrow stromal cells and their more differentiated progeny: a comparative investigation in vitro. Cell Tissue Res 2003;313:281-90.

82 Dennis JE, Carbillet JP, Caplan Al, et al. The STRO-1+ marrow cell population is multipotential. Cells Tissues Organs 2002;170:73-82.

83 Nasef A, Zhang YZ, Mazurier C, et al. Selected Stro-1-enriched bone marrow stromal cells display a major suppressive effect on lymphocyte proliferation. Int I Lab Hematol 2009;31:9-19.

84 Bakondi B, Shimada IS, Perry A, et al. CD133 identifies a human bone marrow stem/progenitor cell sub-population with a repertoire of secreted factors that protect against stroke. Mol Ther 2009;17:1938-47.

85 Harris JR, Fisher R, Jorgensen M, et al. CD133 progenitor cells from the bone marrow contribute to retinal pigment epithelium repair. Stem Cells 2009:27:457-66.

86 Sasaki H, Ishikawa M, Tanaka N, et al. Administration of human peripheral blood-derived CD133+ cells accelerates functional recovery in a rat spinal cord injury model. Spine (Phila Pa 1976.) 2009;34:249-54.

87 Morikawa S, Mabuchi Y, Niibe K, et al. Development of mesenchymal stem cells partially originate from the neural crest. Biochem Biophys Res Commun 2009;379:1114-19.

88 Nagoshi N, Shibata S, Kubota Y, et al. Ontogeny and multipotency of neura crest-derived stem cells in mouse bone marrow, dorsal root ganglia, and whisker pad. Cell Stem Cell 2008;2:392-403.

89 Rice CM, Clavel C, Mazo M, et al. Multipotent adult progenitor cell isolation and proliferation in cytokine and serum free medium conditioned by rat B104 cells. Br J Haematol 2010;148:441-4.

90 Ruckh JM, Zhao JW, Shadrach JL, et al. Rejuvenation of regeneration in the aging central nervous system. Cell Stem Cell 2012;10:96-103.

91 Prockop DJ, Brenner $M$, Fibbe WE, et al. Defining the risks of mesenchymal stromal cell therapy. Cytotherapy 2010;12:576-8.

92 Miura M, Miura Y, Padilla-Nash HM, et al. Accumulated chromosomal instability in murine bone marrow mesenchymal stem cells leads to malignant transformation. Stem Cells 2006;24:1095-103.

93 Dahl JA, Duggal S, Coulston N, et al. Genetic and epigenetic instability of human bone marrow mesenchymal stem cells expanded in autologous serum or fetal bovine serum. Int I Dev Biol 2008:52:1033-42.

94 Tonti GA, Mannello F. From bone marrow to therapeutic applications: different behaviour and genetic/epigenetic stability during mesenchymal stem cell expansion in autologous and foetal bovine sera? Int I Dev Biol 2008:52:1023-32.

95 Alves $\mathrm{H}$, Munoz-Najar $\mathrm{U}$, de WJ, et al. A link between the accumulation of DNA damage and loss of multipotency of human mesenchymal stromal cells. J Cell Mol Med 2009.

96 Kretlow JD, Jin YQ, Liu W, et al. Donor age and cell passage affects differentiation potential of murine bone marrow-derived stem cells. BMC Cell Biol 2008;9:60

97 Crisostomo PR, Wang M, Wairiuko GM, et al. High passage number of stem cells adversely affects stem cell activation and myocardial protection. Shock 2006:26:575-80. 
98 Dominici M, Le BK, Mueller I, et al. Minimal criteria for defining multipotent mesenchymal stromal cells. The International Society for Cellular Therapy position statement. Cytotherapy 2006;8:315-17.

99 Dominici M, Paolucci P, Conte P, et al. Heterogeneity of multipotent mesenchymal stromal cells: from stromal cells to stem cells and vice versa. Transplantation 2009;87:536-42.

100 Burt RK, Loh Y, Pearce W, et al. Clinical applications of blood-derived and marrow-derived stem cells for nonmalignant diseases. JAMA 2008;299:925-36.

101 Grigoriadis N, Lourbopoulos A, Lagoudaki R, et al. Variable behavior and complications of autologous bone marrow mesenchymal stem cells transplanted in experimental autoimmune encephalomyelitis. Exp Neurol 2011;230:78-89.

102 Murphy MP, Lawson JH, Rapp BM, et al. Autologous bone marrow mononuclear cell therapy is safe and promotes amputation-free survival in patients with critical limb ischemia. J Vasc Surg 2011;53:1565-74.
103 Siqueira RC, Messias A, Voltarelli JC, et al. Intravitreal injection of autologous bone marrow-derived mononuclear cells for hereditary retinal dystrophy: a Phase I Trial. RETINA 2011;31:1207-14

104 Savitz SI, Misra V, Kasam M, et al. Intravenous autologous bone marrow mononuclear cells for ischemic stroke. Ann Neurol 2011;70:59-69.

105 Rice CM, Mallam EA, Whone AL, et al. Safety and feasibility of autologous bone marrow cellular therapy in relapsing-progressive multiple sclerosis. Clin Pharmacol Ther 2010;87:679-85.

106 Cottrell DA, Kremenchutzky M, Rice GP, et al. The natural history of multiple sclerosis: a geographically based study. 6 . Applications to planning and interpretation of clinical therapeutic trials in primary progressive multiple sclerosis. Brain 1999; 122(Pt 4):641-7.

107 Tremlett $H$, Paty D, Devonshire V. The natural history of primary progressive MS in British Columbia, Canada. Neurology 2005;65:1919-23. 